\title{
Mitral valve surgery in heart failure: Insights from the Acorn clinical trial
}

\author{
Eugene A. Grossi, MD, and Gregory A. Crooke, MD
}

See related article on page 568 .

From the Department of Cardiothoracic Surgery, NYU School of Medicine, New York, NY.

Received for publication April 27, 2006; accepted for publication May 3, 2006.

Address for correspondence: Eugene A. Grossi, MD, New York University Medical Center, Department of Surgery, 530 First Ave, Suite 9V, Skirball Bldg, New York, NY 10016 (E-mail: grossi@cv.med.nyu.edu).

J Thorac Cardiovasc Surg 2006;132:455-6

0022-5223/\$32.00

Copyright (C) 2006 by The American Association for Thoracic Surgery

doi:10.1016/j.jtcvs.2006.05.013
I $\mathrm{n}$ this issue of the Journal, Acker and colleagues ${ }^{1}$ present some of the outcomes of the CorCap study - specifically, the subgroup analysis of patients who underwent concomitant mitral valve surgery. In this randomized study, the addition of the CorCap device provided enhanced geometric changes in the left ventricular (LV) shape without having a significant additive effect on clinical outcomes.

The most notable information contained in this dataset is the outcomes of the control group: mitral valve surgery in medically optimized patients with significant functional mitral regurgitation, myopathic hearts, and symptomatic congestive heart failure. This subgroup represents an uncontrolled prospective analysis of isolated mitral valve surgery in patients with significant functional mitral insufficiency, New York Heart Association class III or IV, ejection fraction less than 35\% (mean ejection fraction, $23 \% \pm 9 \%$ ), and a dilated LV (mean LV end-diastolic volume, $270.1 \pm 100.3 \mathrm{~mL}$ ). This group had an outstanding 1.6\% 30-day mortality rate and significant improvements in quality of life, exercise performance, and New York Heart Association functional class. Equally as important, mitral valve operations led to improvements in LV volumes, mass, and shape, all consistent with reverse remodeling. Finally, unlike other reports in the literature, the operations were durable, because recurrence of clinically significant MR was uncommon in this patient cohort. ${ }^{2}$ As a result, the authors conclude that the improvement in LV structure and clinical function, along with a very low mortality rate, justifies strong consideration for offering MV surgery to heart failure patients who are on an optimal medical regimen.

These are excellent results, and from the perspective of the CorCap, it would be hard to measure any additional clinical benefit from the CorCap device that would advocate its addition to mitral valve surgery. The outcomes do, however, support the hypothesis that patients with cardiomyopathy benefit from the surgical correction of the functional mitral insufficiency. The results of this study add to a growing experience of clinical improvement with mitral valve repair. ${ }^{3}$ Unfortunately, there still is considerable skepticism about the safety and efficacy of mitral valve surgery in patients with heart failure. Earlier this year, the American College of Cardiology published a continuing medical education course entitled "Mitral Valve Surgery for CHF: A Failed Concept?" which taught that "surgical treatment of FMR results in little if any survival benefit or reverse remodeling" and "it is possible that MVR for FMR reduces symptoms and improves exercise tolerance but conclusive data to support this hypothesis do not exist." available data suggest that the current enthusiasm for surgical treatment of FMR should be reconsidered until the results of a prospective trial confirms its efficacy." Last year, another study, although nonrandomized and retrospective, failed to show a survival benefit in a similar patient cohort. ${ }^{5}$ As recently as 1998, American Heart Association/American College of Cardiology guidelines even questioned the appropriateness of surgical therapy in these patients. "Determining the surgical candidacy of the symptomatic patient with MR and far-advanced LV dysfunction is a common clinical dilemma. If mitral valve repair appears likely, surgery should still be contemplated, provided ejection fraction is $>30 \% . "{ }^{\prime 6}$ Last year, this approach was still considered "under development" by American Heart Association/American College of Cardiology guidelines for the treatment of heart failure. ${ }^{7}$ 
Although the current patient cohort is not randomized against medical therapy, the study does directly address the preceding concerns with data from a prospective, multicenter, observational study. This provides strong data to counter the strong negative impression in the community of the surgical treatment outcomes of MR in patients with impaired LV function. There are several things that we do not learn from this study. First, there is no medical control arm to absolutely determine the benefit of mitral valve surgery. Second, one is unable to extend these findings to patients with functional ischemic mitral insufficiency, because greater than $90 \%$ of these patients had nonischemic cardiomyopathies. Finally, no insights can be gleaned as to which patients benefit from mitral repair over mitral replacement or the ability to predict in which patients valve repair is likely to fail.

\section{References}

1. Acker MA, Bolling S, Shemin R, Kirklin J, Oh JK, Mann DL, et al. Mitral valve surgery in heart failure: Insights from the Acorn Clinical Trial. J Thorac Cardiovasc Surg. 2006;132:568-77.
2. McGee EC, Gillinov AM, Blackstone EH, Rajeswaran J, Cohen G, Najam F, et al. Recurrent mitral regurgitation after annuloplasty for functional ischemic mitral regurgitation. J Thorac Cardiovasc Surg. 2004;128:916-24.

3. Bolling SF, Pagani FD, Deeb GM, Bach DS. Intermediate-term outcome of mitral reconstruction in cardiomyopathy. $J$ Thorac Cardiovasc Surg. 1998;115:381-6.

4. Gorman RC. Mitral valve surgery for CHF: a failed concept? Cardiosource: American College of Cardiology Web site. Available at: http://www. cardiosource.com/expertopinions/hottopics/article.asp?paperID $=219$. Accessed 4/25/06.

5. Wu AH, Aaronson KD, Bolling SF, Pagani FD, Welch K, Koelling TM Impact of mitral valve annuloplasty on mortality risk in patients with mitral regurgitation and left ventricular systolic dysfunction. J Am Coll Cardiol. 2005;45:381-7.

6. Guidelines for the management of patients with valvular heart disease executive summary. A report of the American College of Cardiology/ American Heart Association Task Force on Practice Guidelines (Committee on Management of Patients With Valvular Heart Disease). Circulation. 1998;98:1949-84.

7. Guideline update for the diagnosis and management of chronic heart failure in the adult: a report of the American College of Cardiology/ American Heart Association Task Force on Practice Guidelines (writing committee to update the 2001 Guidelines for the Evaluation and Management of Heart Failure): developed in collaboration with the American College of Chest Physicians and the International Society for Heart and Lung Transplantation-endorsed by the Heart Rhythm Society. Circulation. 2005;112:e154-235. 